\title{
Respiración artificial: autoritarismo e ditadura no romance argentino contemporâneo
}

\author{
Respiración artificial: autoritarism and dictatorship in the \\ contemporaneous argentinean novel
}

\section{Respiración artificial: autoritarismo y ditadura en la novela argentina contemporánea}

\section{Bárbara Loureiro Andreta ${ }^{\text {a }}$ (D) \\ ${ }^{\text {a }}$ Licenciada em Filosofia pela Universidade Federal de Santa Maria (UFSM) e graduada em Psicologia pelo Centro Universitário Franciscano (UNIFRA). É doutoranda do Programa de Pós-Graduação em Letras da UFSM, bolsista CAPES/DS, Santa Maria, RS, Brasil - E-mail: barbaraandr@hotmail.com}

Resumo: O romance Respiración artificial foi escrito por Ricardo Piglia e veio a público no ano de 1980, ainda durante a ditadura argentina (1976-1983). Este trabalho tem, como objetivo, analisar como a temática da ditadura aparece em Respiración artificial, considerando-se as conexões que esta apresenta com outros momentos históricos e as referências a outros autores e obras.

Palavras-chave: Respiración artificial. Ricardo Piglia. Ditadura argentina.

\begin{abstract}
Respiración artificial is a novel by Ricardo Piglia, and first published in 1980, during the Argentinean Dictatorship (1976-1983). This paper aims to analyze how dictatorship theme is developed in Respiración artificial, paying an special attention to the connexion that this masterpiece has when it comes to others historical moments, as well as direct and indirect literary quotations and references to other writers.
\end{abstract}

Keywords: Respiración artificial. Ricardo Piglia. Argentinean Dictatorship.

Resumen: La novela Respiración artificial fue escrita por Ricardo Piglia, y llevada al público en 1980, durante la dictadura argentina (1976-1983). Este trabajo tiene como objetivo analizar cómo la temática de la dictadura se muestra en Respiración artificial, teniendo en cuenta las conexiones que esta obra tiene con otros momentos históricos y las referencias a otros autores y obras.

Palabras-clave: Respiración artificial. Ricardo Piglia. Dictadura argentina.

\section{Como citar o artigo:}

ANDRETA, Bárbara Loureiro. Respiración artificial: autoritarismo e ditadura no romance argentino contemporâneo. Revista de Ciências Humanas, v.52, 2018. DOI: 10.5007/2178-4582.2018.44541 obra, forneça um link para a licença, e indicar se foram feitas alterações. 


\section{INTRODUÇÃO}

O escritor e crítico literário argentino Ricardo Piglia (1940-2017) iniciou sua trajetória como escritor durante a década de 1960, em meio ao denominado boom da literatura latino-americana. Estréia em 1967, com o livro de contos Jaulario (La Habana: Casa de las Américas) (PIGLIA, 1967a), que recebe uma menção especial na categoria conto pela Casa de las Américas, no mesmo ano ${ }^{1}$. Ricardo Piglia publicou também a coletânea de contos Nombre falso (PIGLIA, 1975), Cuentos morales (PIGLIA, 1995), e os romances Plata quemada (Prêmio Planeta) (PIGLIA, 1997), Blanco nocturno (PIGLIA, 2010) e El camino de Ida (PIGLIA, 2013). Entretanto, a obra que lhe assegurou reconhecimento internacional e o seu lugar entre os grandes novelistas latino-americanos foi Respiración artificial (PIGLIA, 1980), publicado durante a ditadura argentina. A obra de Ricardo Piglia sempre foi marcada por intensa experimentação em sua linguagem, seguindo o exemplo de outros grandes escritores argentinos da segunda metade do século XX, tais como Jorge Luis Borges, Julio Cortázar e Manuel Puig, tornando, assim, a questão acerca das relações entre arte e sociedade uma discussão presente no cenário literário argentino.

O romance Respiración artificial (PIGLIA, 1980) inicia-se com uma troca de correspondências entre o jovem escritor Emílio Renzi ${ }^{2}$ e seu tio, o historiador Marcelo Maggi, em função de um romance escrito por Emílio Renzi, no qual o escritor narra a história que lhe foi contada sobre seu tio, que não via desde muito pequeno, visto que tinha partido com uma dançarina de cabaré, abandonando assim, sua tia. O contato de Emílio Renzi com seu tio tem como ponto central a busca de um arquivo, que pertenceu a Enrique Osorio, e que Marcelo Maggi deseja recuperar. O contato entre Marcelo Maggi e Emílio Renzi leva o jovem escritor a um encontro com Tardewski, um filósofo, imigrante polonês. Os dois têm uma longa conversa, na qual Tardewski relata a Emílio Renzi fatos de sua vida, sua experiência como imigrante na Argentina, além de questões referentes à literatura e à filosofia.

$\mathrm{O}$ romance se passa durante a última ditadura militar na argentina no século $\mathrm{XX}$, que teve início em 1976 e durou até o ano de 1983, chamada de "Proceso de Reorganización Nacional". Entretanto, durante a narrativa, há referências a outros governos autoritários em regime de exceção: a ditadura Rosas, na Argentina, e a ditadura nazista na Europa. Respiración artificial pode ser

\footnotetext{
${ }^{1}$ Uma segunda edição do livro é publicada ainda em 1967, em Buenos Aires, sob o título La invasión (Editorial J. Álvarez: Buenos Aires, 1967b). Essa segunda reedição contém um conto novo, intitulado "Mi amigo", ademais de importantes modificações em outros contos já publicados na edição anterior.

${ }^{2}$ Emilio Renzi é o alter ego do próprio Ricardo Piglia, que aparecem desparece e reaparece ao longo de inúmeras de suas narrativas longas, às vezes com mais, às vezes com menos protagonismo. O nome do alter ego provém deum jogo de palavras especular que o autor faz como seu próprio nome de batismo, Ricardo Emilio Piglia Renzi. O retorno triunfal desse alter ego ocorre com o início da publicação de Los diarios de Emilio Renzi (três volumes nos quais Piglia publica seus diários pessoais, iniciados aos dezesseis anos de idade). O primeiro desse volumes, intitulado Los diarios de Emilio Renzi: los años de formación, já se encontra publicado (Barcelona: Anagrama, 2015).
} 
considerado, desse modo, o que Edgardo Berg caracterizou, em sua obra Poéticas en suspenso, migraciones narrativas en Ricardo Piglia, Andrés Rivera y Juan José Saer ${ }^{3}$ como testimonio ficcional, visto que o efeito de distanciamento ${ }^{4}$ de Bertold Brecht, evocados como necessários no longo diálogo presente na segunda parte de Respiración artificial, permitem afastá-lo de um romance de testemunho, uma vez que não há testemunhas diretas e a ideia de distância histórica, expressa pelas personagens Marcelo Maggi, Emílio Renzi e Tardewski relativiza o real e a verdade (GROTTO, 2010, p. 3).

A escrita de Ricardo Piglia está nesse lugar entre o real e o irreal, entre a vida e a literatura, entre o biográfico e o romanesco. Nos espaços em que se espera a verdade - o ensaio, a crítica, a entrevista, o diário - têm-se a invenção, e nos espaços em que se espera a invenção - o romance -, tem-se a história cultural e política argentina e as constantes remissões autobiográficas (SCHWARTZ, 2013, p. 84-85). Um exemplo de remissão autobiográfica é a reconstrução de trechos da vida de Enrique Osorio. Enrique Osorio era secretário de Rosas $^{5}$ - que era um federalista - mas fazia espionagem para os unitários ${ }^{6}$, enviava informações secretas a Félix Frías ${ }^{7}$ em Montevidéu e colaborou na conspiração de $\mathrm{Maza}^{8}$, que foi descoberta e reprimida, da qual teve que fugir e se esconder. Tendo sido membro da Geração de $1937^{9}$, Enrique Osorio esteve em uma situação similar a Emilio Renzi e Marcelo Maggi, deixando seus escritos com esposa. Seus escritos formam o arquivo que está em poder do senador Luciano Osorio e que passará às mãos de Marcelo Maggi e, finalmente, às mãos de Emilio Renzi (PÉREZ, 2013, p. 228).

\footnotetext{
${ }^{3}$ BERG, Edgardo. Poéticas em suspenso: migraciones narrativas em Ricardo Piglia, Andrés Rivera y Juan José Saer. Buenos Aires: Biblos, 2002.

${ }^{4} \mathrm{O}$ efeito de distanciamento, ou Verfremdungseffekt não deve ser entendido, segundo Althusser (2007), apenas como um efeito de técnicas teatrais, mas como um efeito geral da revolução da prática teatral. Não se trata se trata, segundo o autor, de mudar de lugar, de deslocar alguns pequenos elementos no jogo dos atores, mas de um deslocamento que afeta o conjunto das condições do teatro. Trata-se, portanto, de um conjunto de deslocamentos, que constituem esta nova prática. Entre todos esses deslocamentos, há um deslocamento fundamental, que é a causa de todos os outros deslocamentos e que resume, ao mesmo tempo, todos os outros, a saber: o deslocamento do ponto de vista (ALTHUSSER, 2007, p. 5758).

${ }^{5}$ Durante o governo Maza, houve o assassinato de Juan Facundo Quiroga, em Barranca Yaco. A notícia comoveu Buenos Aires e precipitou a queda de Maza, que renunciou em 07/03/1835. No mesmo dia, Rosas foi nomeado governador de Buenos Aires, sendo-lhe outorgado, por cinco anos a "soma do poder público", devendo ele conservar, defender e proteger a religião católica, e advogar e sustentar a causa do Federalismo (GONZÁLEZ, 2006, p. 7).

${ }^{6} \mathrm{O}$ processo de emancipação política argentina teve início em 1810. Diante das tensões frente ao processo emancipatório, ocorreram divisões políticas onde hoje é a Argentina. Os federalistas defendiam maior poder e maior liberdade para os caudilhos interioranos, enquanto os unitários defendiam a centralização do poder a partir de Buenos Aires. Esta oposição marcou o país durante todo o século XIX (FREITAS NETO, 2009, p. 191).

${ }^{7}$ Félix Frías nasceu em Buenos Aires, em 1816. Estudou Direito e fez parte da "Geração de 37". Em 1838, emigrou para o Uruguai, em função de perseguições sofridas pela ditadura Rosas na Argentina. Nesta época, em solo uruguaio, já viviam muitos argentinos que planejavam tirar Rosas do poder (TOMÁS AUZA, 1999, p. 7-8).

${ }^{8}$ A Conspiração de Maza foi como ficou conhecida uma conspiração que tinha como objetivo depor e assassinar Rosas, então governador da província de Buenos Aires. Foi descoberta e reprimida em 1839, e seu delator foi Nicolás Martínez Fontes, um espião que estava infiltrado no grupo de conspiradores (GONZÁLEZ, 2006, p. 10).

${ }^{9}$ A "Geração de 37" era constituída de um grupo de políticos e intelectuais, marcados pelo iluminismo, que propunham um regime republicano liberal para a Argentina. Formavam, assim, um grupo de oposição ao governo ditatorial de Juan Manuel de Rosas (1829-1859) (SILVA, 2003, p. 256).
} 
Hutcheon (1988) defende que a escrita pós-moderna da história e da literatura ensinou que ambas - história e ficção - são discursos, que ambas constituem sistemas de significação pelos quais é possível significar o passado. Segundo ela, o significado e a forma não estão nos eventos, mas nos sistemas que fazem daqueles "eventos" passados, "fatos" históricos; Hutcheon (1988) acrescenta ainda que não se trata de uma "fuga desonesta da verdade", mas de um reconhecimento da função de construção de significados dos constructos humanos.

No que toca aos elementos formais da obra, percebe-se que a narrativa é dividida em dois momentos principais: a primeira parte da narrativa apresenta-se de forma epistolar, e a segunda apresenta-se de forma mais dialógica. A primeira parte, na qual predomina a forma epistolar, com trocas de cartas entre o historiador Marcelo Maggi e seu sobrinho. Emilio Renzi escreve um romance no qual conta a história de seu tio, Marcelo Maggi. O romance de Emílio Renzi vem a público em abril e 1976 e, logo após a publicação de seu romance, o escritor recebe uma carta de seu tio - Marcelo Maggi - e é neste estado de coisas que se inicia a história de Respiración artificial.

Emílio Renzi não conhece realmente seu tio, uma vez que este só o visitou uma vez quando ele era um bebê de dois meses de idade, e nunca mais o viu. O que Emílio sabe sobre seu tio é através de histórias contadas pelos seus familiares, e de investigações que fez sobre sua vida para escrever seu romance La prolijidad de lo real. Sendo assim, seu tio encarna o peso do real, da história, em Respiração artificial.

A segunda parte do livro desenvolve-se com base em um diálogo entre Emílio Renzi e o filósofo polonês Tardewski, amigo de seu tio, que conta a Emílio Renzi coisas sobre sua própria vida, sobre seu doutorado inacabado, sobre sua fuga da Polônia quando essa foi invadida pelos nazistas durante a Segunda Guerra Mundial. Pérez (2013) aponta que o romance Respiración Artificial introduz uma visão fragmentada e diaspórica da história. Quanto ao tempo da narrativa, pode-se dizer que as histórias relatadas ao longo da narrativa buscam um centro e sua verdade, mas não a encontram. Elas estão relacionadas a outras realidades, associam-se de maneira descontínua e aparentemente casual, muitas vezes entrando em conflito. Há a vinculação de épocas distantes no tempo, como a relação da tirania do Governo Rosas com a ditadura vivenciada no momento da narrativa - esta vinculação ocorre principalmente através do arquivo procurado pelos personagens. No ano de 1979, são narrados acontecimentos ocorridos a partir de abril de 1976, no mês seguinte ao golpe militar que mudou a história argentina e que concluiu um capítulo de 50 anos de intervenções militares na sociedade civil, que havia começado em 1930, com o general Uribiru' ${ }^{10}$ (PÉREZ, 2013, p. 221).

\footnotetext{
${ }^{10}$ Em 06/09/1930, o general Uriburu encabeçou um golpe de estado que derrubou o governo constitucional de Hipólito Yrigoyen, estabelendo uma ditadura militar, a primeira de uma série de ditaduras militares argentinas, que se estenderiam até 1983. Destaca-se que a Argentina teve seis golpes de Estado no século XX: 1930, 1943, 1955, 1962, 1966 e 1976. Os quatro primeiros golpes de Estado estabeleceram ditaduras provisórias, enquanto os dois últimos estabeleceram ditaduras duradouras, nas quais os direitos humanos foram altamente violados.
} 
Piglia articulou, ao redor da figura de Maggi, um triângulo narrativo, do qual participam Marcelo Maggi, Emilio Renzi e Volodia Tardewski, de maneira que todos assumem a voz narrativa em diferentes momentos (PÉREZ, 2013, p. 222). Moraes (2009, p. 54) advoga que o narrador do texto de Ricardo Piglia - assim como outros narradores pós-modernos - busca um afastamento, mas o que consegue é um adensamento de seus limites biográficos, de maneira que, nos textos de Ricardo Piglia, a subjetividade beira sempre o biográfico da personagem, da história da literatura, da história argentina, da história ocidental e da própria história do autor. Moraes (2009, p. 54) destaca ainda que o narrador não percorre apenas um tipo de relato; ele multiplica-se em relatos microdesejantes e micropolíticos que recobrem toda a superfície textual de subjetividades amplificadas, variadas e em transformação (MORAES, 2009, p. 54).

Schwartz (2013), por sua vez, dedicou-se ao estudo do narrador em Respiracón artificial, tendo como base o texto El escritor y la tradición: Ricardo Piglia y la literatura argentina, de Fornet (2007), considerado por ele uma das mais importantes obras sobre a produção literária de Ricardo Piglia, e defende uma visão diferenciada das apresentadas anteriormente acerca do narrador em Respiración artificial. Schwartz (2013, p. 84) destaca, já no início de seu texto que delimitar quem está com a palavra, neste romance, exige muito cuidado, visto que nos textos de Ricardo Piglia, as coisas nunca ocorrem como dão a impressão de ser. Schwartz $(2013$, p. 84) salienta que discutir o papel do narrador em Respiración artificial exige que se pense em duas instâncias: a primeira seria a relação que o narrador estabelece com o autor real, e a segunda instância seria o rearranjo do discurso do texto a partir de uma revisão dos disfarces que esse(s) narrador(es) assume(m). Sendo assim, Schwartz (2013, p. 88) retoma o questionamento de Fornet (2007), que procura entender como é possível que o conteúdo dos papéis de Enrique Osorio esteja presentes no texto, uma vez que Emilio Renzi teve acesso a eles apenas ao final da narrativa:

En primer lugar, habría que preguntarse a qué relato se refiere. Parecería que es a la novela misma y que ésta ha debido ser escrita por el propio Renzi, pero en tal caso se trataría de una escritura imposible. La novela, tal como la conocemos, pude ser la materia prima del presunto relato de Renzi, pero difícilmente el relato mismo. Aunque es Renzi quien comienza narrando, poco a poco se va introduciendo voces ajenas a las que él ha tenido acceso de una forma u otra. En el primer capítulo aparecen ya las cartas que le ha enviado Maggi. En el segundo, la voz dominante es la del Senador, pero aún ahí es Renzi quien narra. En el tercero, sin embargo, las cosas se complican: se reproducen fragmentos de los papeles de Osorio y entra la narración de Arocena y la lectura que éste hace de las cartas interceptadas, incluidas algunas de Renzi y Maggi. Pero resulta que Renzi no conoce los papeles de Osorio sino un año después, es decir, cuando Tardewski se los entrega al fino mismo de la novela, mientras que en ningún momento ha podido tener acceso a la figura y las lecturas de Arocena. ¿Cómo es posible entonces que estén en su relato? (FORNET, 2007, p. 90 apud SCHWARTZ, 2013, p. 88). 
De acordo com Schwartz (2013, p. 88), levando-se em consideração a teoria desenvolvida por Fornet (2007), uma das chaves para o entendimento desta questão do narrador de Respiración artificial estaria no tempo transcorrido entre a primeira parte da narrativa e a segunda parte:

\begin{abstract}
Entre el comienzo de una y otra [partes], por cierto, ha trascurrido un año. Si el tiempo de la enunciación comienza en el 1979, la segunda parte se desarrolla en 1980, el mismo año de publicación de la novela. Esa contemporaneidad del relato hace más confuso el problema de su autoría. Podemos pensar que al llegar al punto final, cuando Renzi abre la carpeta con los papeles de Osorio, tiene ante sí toda esa materia prima que va a conformar el texto; pero ese texto, como dije antes, no ha podido ser escrito sino 'vivido' pues, entre otras cosas, se llega a ese punto casi en el mismo momento en que se publica la novela real de Piglia. Es decir, que la lectura que Renzi hace de aquellos papeles prácticamente coincide en el tiempo con la que los primeros lectores de Respiración artificial hicieron de la novela (FORNET, 2007, p. 92-93 apud SCHWARTZ, 2013, p. 88).
\end{abstract}

Schwartz (2013, p. 89) reforça a tese levantada por Fornet (2007), apresenta, então, o que seria, na materialidade textual, uma possível solução para a questão do narrador, ao destacar a seguinte passarem do romance:

Esa fue la primera carta y así empieza verdaderamente esta historia. Casi un año después yo iba hacia él, muerto de sueño en el vagón destartalado de un tren que seguía viaje al Paraguay. Unos tipos que jugaban a los naipes sobre una valija de cartón me convidaron con ginebra. Para mí era como avanzar hacia el pasado y al final de ese viaje comprendí hasta qué punto Maggi lo había previsto todo. Pero eso pasó después, cuando todo terminó; antes recibí la carta y la fotografía y empezamos a escribirnos (PIGLIA, 1992, p. 19).

No trecho citado, a referência "casi un año después" seria um indicativo de que a ida a Concórdia estaria ocorrendo um ano depois das trocas de cartas, do encontro com Tardewski e do acesso aos papéis de Enrique Osorio, assim como "hasta que punto Maggi lo había previsto todo" e “cuando todo terminó" podem ser considerados indicativos de que Marcelo Maggi suspeitava do que o esperava, ou seja, ele suspeitava que poderia ser capturado pela ditadura argentina. Sendo assim, Schwartz (2013, p. 89) corrobora com a tese de Fornet (2007), de que Respiración artificial teria um único narrador e este narrador seria Emílio Renzi.

A trama principal do romance desenvolve-se em uma sociedade dominada pelo terror de Estado, submetida a uma "pacificação" brutal, que proíbe todo o tipo de reunião e associação política, de forma que os personagens se movem em um mundo clandestino e subterrâneo, se escrevem e se visitam, narrando as histórias de seu passado, sempre conscientes da vigilância do poder oficial ( $C f$. PÉREZ, 2013). Devido à situação histórica vivenciada, os personagens vivem em um estado virtual de reclusão e apenas se comunicam por cartas e visitas ocasionais. São personagens que estão sós, sentem um grande vazio e permanecem isolados, refletindo sobre o seu passado. Todos foram vítimas da história: Marcelo Maggi, Tardewski e o senador Luciano Osorio. 
Percebe-se que os personagens desta narrativa estão todos "submersos" em regimes autoritários, tanto no momento presente da narrativa quanto no passado dessa. Marcelo Maggi, como historiador, dedica-se há muitos anos a pesquisar e a tentar reencontrar o arquivo que pertenceu a Enrique Osorio que, possivelmente envolve segredos da Ditadura Rosas e que, em algum momento, esteve em suas mãos e, por algum motivo, se perdeu. Está, ainda, submerso em toda a questão da ditadura argentina da década de 1970, visto que, de acordo com elementos da narrativa, Maggi é vigiado pelos censores do Estado, tendo suas correspondências receptadas. Em Respiración artificial, os personagens nunca operam em um vazio crítico: são constantemente vigiados pelo regime militar argentino, através do censor e espião Arocena, que interfere em suas correspondências, na busca por pistas de atividades subversivas. Este censor é quem encontra chave sobre as atividades de Maggi e o leitor é levado a suspeitar que ele é o responsável pelo desaparecimento de Maggi ao final da obra:

No hay novedades. Espero el contacto. Me quedaré en el Hotel Central Park, 8 th. Y 42. Broadway. Si no hay noticias antes del 20, seguiré las instrucciones 9. 8. Si hay dificultades y tengo que volver, espero un telegrama. Que diga: Felicidades, Raquel (PIGLIA, 1992, p. 99).

Tardewski é um personagem que remete ao expatriado. É um judeu polonês, que estudava na Inglaterra e, em 1939, quando passava as férias na casa da sua família na Polônia, viu seu país ser invadido pela Alemanha. Sendo assim, o jovem Tardewski precisou fugir, abandonando seu país de origem, o país que lhe acolheu para os estudos, o sonho de realizar seu doutorado em Filosofia e, futuramente, tornar-se professor em uma universidade, embarcando em um navio que ele imaginava que ia para os Estados Unidos e que, por fim, chegou à Argentina. Tardewski representa o cidadão que viveu grande parte de sua vida submetido a regimes autoritários, fugiu da Polônia quando da invasão nazista e, no momento presente da narrativa, vive em uma Argentina submetida a uma ditadura. Representa uma pessoa sem lugar definido no mundo, um polonês de nascimento, que viveu muitos anos na Inglaterra e, no momento da narrativa, vive na Argentina, tendo se recusado a rejeitar sua cidadania polonesa.

Por eso era él un hombre moral, dijo Tardewski, y por eso era mi antítesis. Y si le he dicho todo esto es para hacerle ver hasta qué punto el Profesor y yo éramos, uno del otro, el proprio antagonista. Yo, el incrédulo, un hombre que sólo utiliza el pensamiento para poder sobrevivir; él, un hombre de principios, capaz de ser fiel en la vida al rigor de sus ideas. Yo, el desterrado; él, un hombre que nació y va a morir en su propio país (PIGLIA, 1992, p. 211 212).

Percebe-se que os personagens mais velhos tem uma relação muito estreita e já duradoura com regimes autoritários, seja por meio de pesquisas, como é o caso de Marcelo Maggi, seja por meio da vivência pessoal, como é o caso de Tardewski. O personagem mais jovem, Emilio Renzi, também 
está submerso no regime autoritário argentino. Entretanto, parte da sua relação com os regimes ditatoriais ocorre em função de sua experiência, de estar vivendo em um regime ditatorial e parte, em função do que lhe é relatado pelas cartas de seu tio Marcelo Maggi e por Tardewski.

A segunda parte da narrativa de Piglia tem como título "Descartes". Em certo trecho do romance, Tardewski fala a Emílio Renzi que, se o Discurso do método, de Descartes (2006) é o primeiro romance moderno, então, Mein Kampf [Minha luta], de Hitler (1934), seria sua paródia, visto que este segundo apresenta a culminação do racionalismo europeu: "para mí, em cambio, dice Tardewski, Mi lucha es la razón burguesa llevada a su límite más extremo y coherente" (PIGLIA, 1992, p. 188). Hutcheon (1988) considera a paródia a forma pós-moderna perfeita. Segundo ela, com a paródia - assim como com qualquer forma de reprodução - a noção do original como raro, singular e valoroso (em termos comerciais e estéticos) é chamada à questão. Isto não significa que a arte perdeu seu significado e propósito, mas que terá, inevitavelmente, um significado novo e diferente. No caso de Respiración artificial, tem-se a impressão que o personagem tenta defender a ideia de que o racionalismo proposto por Descartes (2006), em Discurso do método, é ressignificada, atingindo níveis maiores em Mein Kampf:

Los dos eran monólogos de un sujeto más o menos alucinado que se disponía a negar toda verdad anterior y a probar de un modo a la vez imperativo e inflexible, en qué lugar, desde qué posición se podía (y se debía) erigir un sistema que fuera a la vez absolutamente coherente y filosóficamente imbatible (PIGLIA, 1992, p. 187-188).

Descartes (2006), em Meditações e no Discurso do método explorou os limites do que possivelmente podia conhecer, sendo assim, propôs o método da dúvida, segundo o qual nada deveria ser aceito como verdadeiro se houvesse a mínima possibilidade de não o ser (WARBURTON, 2013, p. 71). Desta maneira, diante dos fatos duvidosos, Descartes (2006) elaborou, em Discurso do método, preceitos estritos, com a finalidade de encontrar um sentido firme e inalterável, ou seja, o entendimento claro e distinto das coisas. Neste contexto, Grotto $(2010$, p. 12) defende que tanto Ricardo Piglia em Respiración artificial quanto Descartes (2006), em Discurso do método, propõem o desafio da dúvida contra a facilidade de uma resposta única, uma vez que, até o final de Respiración artificial as dúvidas somam-se ininterruptamente (GROTTO, 2010, p. 12).

No final da obra, Tardwski fala a Emílio Renzi sobre um possível encontro entre Franz Kafka e Adolf Hitler, supondo que deste encontro e das conversas entre os dois teria se originado o livro $O$ processo, de Kafka (2008). A hipótese de Tardewski é que Hitler, ao fugir do serviço militar obrigatório, teria se escondido em Praga e lá, conhecido Kafka. Durante suas conversas, Hitler teria apresentado a Kafka suas ideias sobre o Estado, as quais teriam inspirado O processo: "esa novela presenta de un modo alucinante el modelo clásico del Estado convertido en instrumento de terror" (PIGLIA, 1992, p. 205). Sendo assim, Tardewski acreditava que Kafka fez, em sua ficção, o que nem 
Hitler acreditava que pudesse um dia conseguir fazer, e o fez antes mesmo de Hitler (1934) escrever o seu Mein Kampf, onde apresenta suas ideias a respeito do Estado:

Kafka hace en su ficción, antes que Hitler, lo que Hitler le dijo que iba a hacer. Sus textos son la anticipación de lo que veía como posible en las palabras perversas de ese Adolf, payaso, profeta que anunciaba, en una especie de sopor letárgico, un futuro de una maldad geométrica. Un futuro que el mismo Hitler veía como imposible, sueño gótico donde llegaba a transformarse, él un artista piojoso y fracasado, en el Führer. Ni el mismo Hitler, estoy seguro, creía en 1909 que eso fuera posible. Pero Kafka, sí. Kafka, Renzi, dijo Tardwski, sabía oír. Estaba atento al murmullo enfermizo de la historia (PIGLIA, 1992, p. 205).

Nesta referência à obra de Kafka (2008) como precedente do Mein Kampf de Hitler (1934) e do próprio regime nazista na Alemanha, o narrador apresenta não apenas a questão de intertextualidade, mas parece tentar apresentar ao leitor os paradoxos presentes nos regimes autoritários:

[...] el exaltado defensor del militarismo prusiano, el siniestro constructor de una abominable sociedad militarizada, había sido un desertor. Delito máximo al que podía aspirar un alemán, según las leyes nazis. Pero esta paradoja no fue lo más importante, al menos para mí (PIGLIA, 1992, p. 198)

Faz-se importante destacar, ainda no que se refere à intertextualidade, que segundo estudos críticos a respeito de Respiración artificial, o personagem Tardewski seria uma referência ao escritor polonês Witold Gombrowicz ${ }^{11}$, que viveu na Argentina entre 1939 e 1962. Semelhante à situação vivenciada por Tardewski no romance, Gombrowski estava em Buenos Aires em 1939, quando tomou conhecimento da invasão da Polônia pela Alemanha nazista, tomando, então, a decisão de permanecer na Argentina, mesmo sem saber falar espanhol. Naquela época, a Argentina hospedava muitos escritores europeus e estadunidenses, tais como Waldo Frank, Pierre Drieu la Rochelle, José Ortega y Gasset e Roger Callois. Entretanto, o que diferenciava a situação desses escritores da situação de Gombrowicz era o fato de que esses haviam sido convidados pela elite cultural argentina, enquanto Gombrowicz representava o imigrante pobre, que ninguém esperava de braços abertos. Gombrowicz era um escritor europeu desprovido de autoridade literária (KOBYLECKA-PIWONSKA, 2012).

A presença de Tardewski como referência a Gombrowski, em Respiración artificial, encontra ressonância no projeto de Piglia no que se refere à literatura em termos de tensões e lutas, segundo o qual a renovação do cânone literário ocorre mediante o conflito de poéticas:

La literatura nacional es la que organiza, ordena y transforma la entrada de los textos extranjeros y define la situación de lectura. Que yo diga, por ejemplo, que me interesa Brecht o William Gaddis, no significa nada; habría que ver desde donde los leo, en que trama incluyo sus libros, de qué modo ese contexto los contamina, de qué forma puede "recibir" su escritura

\footnotetext{
${ }^{11}$ Ricardo Piglia fez algumas referências a Gombrowicz, tais como seu texto "La novela polaca", publicada em seu livro Formas breves, e o texto "La lengua de los desposeídos", publicado no jornal La Nación, no dia 19/04/2008.
} 
la lengua nacional. En el fondo uno se apropia de ciertos elementos de las obras extranjeras para establecer parentescos y alianzas que son siempre una forma de aceptar o de negar tradiciones nacionales (PIGLIA, 2006, p. 56).

Ewa Kobylecka-Piwonska (2012) destaca que Ricardo Piglia não recorre a Gombrowicz no sentido de ter seus textos como modelo narrativo, mas pelo seu entendimento do fenômeno da literatura e como uma personalidade ou representante de uma postura filosófica ante a vida. Neste contexto, a presença de Tardewski aparece, na obra de Ricardo Piglia, tanto como uma possibilidade de renovação do cânone nacional argentino, mediante o conflito de poéticas, como também como uma forma de dar voz à filosofia de Wittgenstein:

\begin{abstract}
Wittgenstein, que hoy es centro de múltiples reflexiones, era obviamente una figura muy destacada cuando estaba escribiendo Respiración artificial. A mí me capturó muchísimo el grado de intensidad artística de la figura de Wittgenstein. Eso fue lo que me fascinó, el destino que este hombre había sido capaz de asumir, la intensidad dramática de su experiencia; me parecía excesivo ponerlo como centro de una novela, y quizá estaba equivocado. Lo que hice, entonces, fue inventar una especie de pseudo Wittgenstein, que fue Tardewski, una combinación de Gombrowicz con Wittgenstein (PIGLIA apud PELLEGRINI; MONDER; JEFTANOVIC, 2010, n.p.).
\end{abstract}

O retorno à filosofía wittgensteiniana fica evidente no texto de Ricardo Piglia em diversos momentos, mas se destaca, especialmente, quando Tardewski pronuncia a frase "sobre aquello de lo que no se puede hablar, hay que callar" (PIGLIA, 2006, p. 163), justamente a frase que encerra o Tractatus logico-philosophicus ${ }^{12}$ de Wittgenstein (1968), e que demonstra que as questões mais importantes sobre ética estão acima dos limites do entendimento humano. Sendo assim, o cunho wittgensteiniano evidencia-se não necessariamente no que Tardewski e Emílio Renzi conversam, mas especialmente, naquilo que não conversam:

Como usted ha comprendido, dice ahora Tardewski, si hemos hablado tanto, si hemos hablado toda la noche, fue para no hablar, o sea, para no decir nada sobre él, sobre el Profesor. Hemos hablado y hablado porque sobre él no hay nada que se puede decir (PIGLIA, 2006, p. 210).

O não falar, e a referência a "no hay nada que se puede decir" apontam, neste caso, a uma dimensão ética, uma vez que o silêncio não está a serviço de esconder questões éticas carentes de sentido, mas os problemas de importância fundamental, os únicos que realmente valem a pena, de acordo com Wittgenstein. O silenciamento sobre Marcelo Maggi, desta forma, leva o leitor a pensar que o que estava para lhe acontecer (a possibilidade de captura pela ditadura argentina e talvez, a situação vivenciada no país) eram vistas como problemas de importância fundamental para Tardewski e Emílio Renzi.

12 “O que não se pode falar, deve-se calar” (WITTGENSTEIN, 1968, p. 129). 
O silenciamento de Tardewski e Emílio Renzi no que diz respeito a Marcelo Maggi deixa, ao final da narrativa, o enigma quanto ao seu destino. Entretanto, outro enigma permanece inconclusivo: não se sabe por que Marcelo Maggi se desfaz de um arquivo que tanto valoriza, que segredos ele contém, que papel tem este arquivo na resistência contra o regime militar e porque ele desaparece. $\mathrm{O}$ romance 'planta' tais enigmas sem os resolver, enigmas que só poderão ser elucidados no futuro da história de seu sobrinho, Emilio Renzi, que leva o arquivo do professor ao final do romance. Os leitores, que sabem que o exército perseguiu e assassinou os opositores e revolucionários - ainda que não conheçam a história do professor - são induzidos a crer que Marcelo Maggi estava implicado na luta revolucionária de alguma maneira, sabia que o exército também buscava tal arquivo, e queria ter acesso a este antes que o exército o pegasse.

Além desta questão que permanece inconclusiva até o final da narrativa, Respiración artificial contém pistas, algumas mais, outras menos explícitas, que apontam em uma determinada direção, e se pode pensar que tenham sido deixadas ali para que essa direção fosse seguida (SCHWARTZ, 2013, p. 86). Uma das pistas seria a dedicatoria do romance: "A Elías y a Rubén, que me ayudaron a conocer la verdad de la historia" (PIGLIA, 1992, p. 3). Schwartz (2013, p. 86) aponta que a dedicatória do romance seria um caminho ironicamente antecipado, pois de acordo com suas pesquisas, os homenageados Elías e Rubén teriam sido dois desaparecidos do regime militar argentino e, na dedicatória, Ricardo Piglia anuncia que eles o ajudaram a conhecer a "verdade da história".

Cabe trazer à discussão Eco (1991) que, em seu texto A obra aberta, considera que toda obra de arte é aberta porque não comporta apenas uma interpretação. A “obra aberta" não é uma categoria crítica, mas um modelo teórico para tentar explicar a arte contemporânea. Assim, qualquer referencial teórico usado para analisar a arte contemporânea não revela suas características estéticas, mas apenas um modo de ser desta obra segundo seus próprios pressupostos. Toda obra de arte contemporânea possibilita várias interpretações e, ao mesmo tempo, mantém suas singularidades de obra de arte acabada inalteradas. A obra aberta pode apresentar-se de várias formas, ficando o seu entendimento a critério de quem aprecia a obra, ou no caso da literatura, a critério do leitor.

No fundo, a forma torna-se esteticamente válida na medida em que pode ser vista e compreendida segundo multíplices perspectivas, manifestando riquezas de aspectos e ressonâncias, sem jamais deixar de ser ela própria (um sinal de trânsito, ao invés, só pode ser encarado de maneira única e inequívoca, e se for transfigurado por alguma interpretação fantasiosa deixa de ser aquele sinal com aquele significado específico). Neste sentido, portanto, uma obra de arte, forma acabada e fechada em sua perfeição de organismo perfeitamente calibrado, é também aberta, isto é, passível de mil interpretações diferentes, sem que isso redunde em alteração de sua irreproduzível singularidade. Cada fruição é, assim, uma interpretação e uma execução, pois em cada fruição a obra revive dentro de uma perspectiva original (ECO, 1991, p. 40). 
Sendo assim, Eco (1991) destaca que o autor produz uma obra acabada em si e deseja que tal obra seja compreendida e fruída da maneira como a produziu; entretanto, o apreciador da obra de arte, ou o leitor de um livro, carrega em si uma bagagem pessoal, social, cultural e política, de forma que sua sensibilidade artística será condicionada e determinada por todos estes fatores que não dependem do artista, da obra, e muitas vezes nem mesmo do próprio leitor ou apreciador da obra.

O não comparecimento de Marcelo Maggi ao encontro com Emilio Renzi e Tardewski é um exemplo disso, visto que os leitores que tem algum conhecimento da história argentina do século XX são induzidos a pensar que Marcelo Maggi foi capturado pela ditadura argentina, enquanto os leitores que não possuem este conhecimento histórico podem pensar que Marcelo Maggi simplesmente desistiu do encontro. O não comparecimento de Marcelo Maggi no encontro fica como um ponto em aberto na obra, possibilitando diversas interpretações, as quais podem variar de acordo com outros conhecimentos prévios que o leitor tenha.

A referência a Wittgenstein, bem como a fala de Tardewski ao se referir a Marcelo Maggi “porque sobre él no hay nada que se puede decir” (PIGLIA, 2006, p. 210) - também podem ter interpretações variadas, mudando de acordo com as "bagagens" do leitor. Para um leitor que não tenha conhecimento da teoria de Wittgenstein, é possível que esta referência de Tardewski a Marcelo Maggi beire o descaso para com o amigo. Entretanto, levando-se em consideração o filósofo que é constantemente lembrado na segunda parte da narrativa, inclusive por ter sido orientador de Tardewski, pode-se pensar esse silenciamento como o encobrimento dos únicos problemas que realmente valem a pena, o que aponta para uma dimensão ética da narrativa.

Por fim, pode-se pensar a obra Respiración artificial como um texto rizomático, de acordo com a teoria de Deleuze e Guattari (1995). Segundo os autores, assim como ocorre com os rizomas, que possuem o caule principal e diversas ramificações, um livro possui linhas de articulação e territorialidades e também linhas de fuga, movimentos de desterritorialização e desestratificação.

Neste sentido, Respiración artificial é uma obra conectável e heterogênea, uma vez que se conecta com outras cadeias, apresentando questões relacionadas à política, à história, à literatura e à filosofia, através de referências a diferentes momentos históricos, a ditaduras argentinas passadas e ao nazismo na Europa, a diversos nomes da literatura argentina e mundial e a referências a diversos filósofos. A temática da ditadura é, assim, revisitada por Ricardo Piglia, através de conexões feitas com outros momentos históricos. A conexão com eventos passados, tais como a Ditadura Rosas e o nazismo na Europa, ajuda na compreensão da situação vivenciada pelos personagens, da vida em uma sociedade dominada pelo terror de Estado e sob a constante vigilância do regime militar argentino. 


\section{REFERÊNCIAS}

ALTHUSSER, Loius. Sobre Brecht e Marx. Crítica marxista (UNICAMP). Vol. 24, 2007, p. 51-62. Trad. Danilo Enrico Martuscelli. Disponível em:

http://www.ifch.unicamp.br/criticamarxista/arquivos_biblioteca/artigo247artigo3.pdf. Acesso em: $24 / 05 / 2015$.

DESCARTES, René. Discurso do Método. Trad. Ciro Mioranza. São Paulo: Escala, 2006.

DELEUZE, Guilles; GUATTARI, Felix. Rizoma. In: . Mil platôs. São Paulo: Ed. 34, 1995.

Vol. 1.

ECO, Umberto. A poética da obra aberta. In: . A obra aberta. São Paulo: Perspectiva, 1991.

FORNET, Jorge. El escritor y la tradición: Ricardo Piglia y la literatura argentina. Buenos Aires: Fondo de Cultura Económica, 2007.

FREITAS NETO, João Alves de. A formação da nação e o vazio na narrativa argentina: ficção e civilização no século XIX. Esboços (UFSC), n. 20, 2009, p. 189-209. Disponível em:

http://periodicos.ufsc.br/index.php/esbocos/article/download/10249/9534. Acesso em: 28/04/2015.

GONZÁLEZ, Cristina Teresa. Relatos del terror en Buenos Aires, 1833-1842. Anuario del Instituto de Historia Argentina. V. 6, 2006, p. 77-96. Disponível em:

http://www.memoria.fahce.unlp.edu.ar/art_revistas/pr.56/pr.56.pdf. Acesso em: 25/05/2015.

GROTTO, Lívia. A segunda história de Respiración artificial. Escrita. N. 11, 2010, p. 1-14.

Disponível em: http://www.maxwell.vrac.puc-rio.br/16358/16358.PDF. Acesso em: 24/05/2015.

HITLER, Adolf. Minha luta. Trad. J. de Matos Ibiapina. Porto Alegre: Globo, 1934.

HUTCHEON, Linda. Historicizing the Postmodern: The Problematizing of History. In: . A

Poetics of Postmodernism: History, Theory, Fiction. London: Routledge, 1988, p. 87-101.

KAFKA, Franz. O processo. Trad. Marcelo Backes. Porto Alegre: L\&PM, 2008.

KOBYLECKA-PIWONSKA, Ewa. Ricardo Piglia, lector de Witold Gombrowicz. Neophilologus. V. XCVI. N. 3, 2012. Disponível em:

http://dspace.uni.lodz.pl:8080/xmlui/bitstream/handle/11089/2719/springer\%20article.pdf?sequence $=1$. Acesso em: 26/05/2015. 
MORAES, Alexandre Jairo Marinho. Respiração artificial: história, tradição e hibridismo em textos de Ricardo Piglia. Ipotesi, Vol. 6, n. 2, 2009, p. 51-58. Disponível em:

http://www.ufjf.br/revistaipotesi/files/2009/12/Respira\%C3\%A7\%C3\%A3o-artificial1.pdf. Acesso em: 24/05/2015.

PELLEGRINI, Marcelo, MONDER, Samuel, \& JEFTANOVIC, Andrea. Conversación con Ricardo Piglia, 2010. Disponível em: http://letras.s5.com/mp010810.html. Acesso em: 26/05/2015.

PÉREZ, Alberto Julián. Respiración artificial: el escritor y el terrorismo de Estado. Latinoamérica (Universidad Nacional Autónoma de México). N. 56, 2013, p. 219-243. Disponível em:

http://www.cialc.unam.mx/web_latino_final/archivo_pdf?Lat56-219.pdf. Acesso em: 26/04/2015.

PIGLIA, Ricardo. Jaulario. La Habana: Casa de las Américas, 1967a. Jaulario).

. La invasión.: Buenos Aires: Editorial J. Álvarez, 1967b. (Edição revista e aumentada de . Nombre falso. México: Siglo XXI, 1975.

. Respiración artificial. Buenos Aires: Editorial Pomaire, 1980.

PIGLIA, Ricardo. Respiración artificial. Buenos Aires: Editorial Sudamericana, 1992. 1995.

. Cuentos morales. Introducción de Adriana Rodríguez Pérsico. Buenos Aires: Espasa Calpe,

. Plata quemada. Buenos Aires: Planeta, 1997.

PIGLIA, Ricardo. Crítica y ficción. Buenos Aires: Anagrama, 2006.

PIGLIA, Ricardo. La lengua de los desposeídos. La Nación (2008). Disponível em: http://www.lanacion.com.ar/1004590-la-lengua-de-los-desposeidos. Acesso em: 26/05/2015.

. Blanco nocturno. Barcelona: Anagrama, 2010.

. El camino de Ida. Barcelona: Anagrama, 2013. 
PIGLIA, Ricardo. Los diários de Emilio Renzi: los años de formación. Barcelona: Anagrama, 2015.

SCHWARTZ, Adriano. Biografia de uma ficção: o romance dentro do romance em Respiração artificial, de Ricardo Piglia. Revista USP. N. 97, 2013, p. 82-91. Disponível em: http://www.revistas.usp.br/revusp/article/view/61688/64577. Acesso em: 24/05/2015.

SILVA, Josinei Lopes da. Luzes e sombras na construção da nação argentina: os manuais da história nacional (1868-1912). História, v. 22, n. 2, 2003, p. 255-260. Disponível em:

http://www.scielo.br/scielo.php?script=sci_arttext\&pid=S0101-90742003000200016. Acesso em: 28/04/2015.

TOMÁZ AUZA, Néstor. Felix Frías: legislador de la conciliación. Buenos Aires: Círculo de Legisladores de la Nación Argentina, 1999.

WARBURTON, Nigel. Uma breve história da Filosofia. Porto Alegre: L\&PM Pocket, 2013.

WITTGENSTEIN, Ludwig. Tractatus Logico-Philosophicus. São Paulo: EDUSP, 1968.

\begin{tabular}{cl}
\hline Histórico & $\begin{array}{l}\text { Recebido em: 9-5-2016 } \\
\text { Revisado em: 9-1-2018 } \\
\text { Aceito em: } 25-6-2018\end{array}$ \\
\hline Financiamento & CAPES/DS; PNPD/CAPES (bolsa de pós-doutoramento)
\end{tabular}

